\title{
Multipoint Background Analysis for Chemical Dating of Monazite
}

\author{
Ji-Qiang Cui ${ }^{1}$, Shui-Yuan Yang ${ }^{1}$, Shao-Yong Jiang ${ }^{1,2}$, Jing Xie $^{3}$ \\ 1. State Key Laboratory of Geological Processes and Mineral Resources, China University of \\ Geosciences, Wuhan, PR China. \\ 2. Faculty of Earth Resources and Collaborative Innovation Center for Scarce and Strategic Mineral \\ Resources, China University of Geosciences, Wuhan, PR China. \\ 3. Key Laboratory of Continental Collision and Plateau Uplift, Institute of Tibetan Plateau Research, \\ Chinese Academy of Sciences, Beijing, PR China.
}

The chemical dating of monazite is a method to analyze the concentrations of $\mathrm{U}, \mathrm{Th}$ and $\mathrm{Pb}$ in monazite by electron probe microanalysis (EPMA). At present, there are two computing methods: (a) The mathematic statistics of a few EPMA analysis data to obtain a geologically meaningful age [1]; (b) The Chemical Th-U-total $\mathrm{Pb}$ Isochron Method (CHIME) [2]. However, it is a prerequisite to accurately determinate $\mathrm{U}, \mathrm{Th}$ and $\mathrm{Pb}$ contents of monazite for using the above two computing methods.

In this paper, the factors affecting the background measurement, such as interference and fitting model, were studied. The aim of the study was to obtain a method for accurately measuring the background. The method was developed using a JEOL JXA-8100 EPMA equipped with four wavelength-dispersive spectrometers at State Key Laboratory of Geological Processes and Mineral Resources, China University of Geosciences (Wuhan). The studied RW-1 monazite that was a natural yellowish-brown crystal sampled from a pegmatite dyke located in the Landsverk 1 quarry situated in the Evje-Iveland district, south Norway, with a weighted mean ${ }^{207} \mathrm{~Pb} /{ }^{235} \mathrm{U}$ age of $904.15 \pm 0.26 \mathrm{Ma}$ (95\% confidence level) [3].

$\mathrm{Pb}$ mainly derived from $\mathrm{Th}$ decay in monazite. The content of $\mathrm{Pb}$ in monazite is very low, and it is always a significant challenge to analyze trace element by EPMA. Therefore, precise and accurate determination of $\mathrm{Pb}$ in monazite is the key for EPMA chemical dating of monazite. The measurement of the background is vitally important for trace element analysis. In EPMA, the two-point background interpolation method is often used, especially for major-element analysis. However, the background shape of some elements is not a straight line, but a curve. The two-point background interpolation method will significantly affect the accuracy of trace elements when the background line is a curve or other major element peaks are near the trace element peak [4-6]. In addition, because monazite is rich in rare earth elements, there is serious interference (absorption edges of a major element, minor peaks, etc.) on background, and can dramatically affect the results if underestimated. To determine the shape of the background slope and search for potential interference, a detailed wavelength scanning is necessary, and background intensities can be extracted directly from scan data by regression [5]. However, detailed wavelength scanning is time-consuming. For this reason, multipoint background (MPB) method was proposed to improve the working efficiency and simplify the workflows. Several points on both sides of the interesting element peak were chosen to determine, and background value is calculated by regression. Sufficient background positions can be selected on both sides of the peak, and the outlier point(s) with the maximum positive deviation from the specified fit can be removed to obtain the lowest background value. However, simply removing the positive anomaly point(s) may get a lower calculated background value than accuracy value, as the negative anomaly point(s) may also exist. 
Here, we choose $15 \mathrm{kV}$ accelerating voltage, $300 \mathrm{nA}$ beam current and $10 \mu \mathrm{m}$ beam diameter as the experimental conditions. According to the results of wavelength scanning, 16 points on both sides of the $\mathrm{Pb}-\mathrm{M} \alpha$ peaks were chosen to determine the background value (Fig. 1a). The counts detected were converted to counts per second and then fitted into a curve equation. In this experiment, a quadratic polynomial is used to fit the background. The resulting curves were compared to those obtained using the traditional two-point background method (Fig. 1b). After the equation of the fitted curve was obtained, the spectrometer position of the peak was regarded as a variable and brought into the equation, after which the background count at the spectrometer position of the peak can be calculated from the equation of the fitted curve. The net on peak count is obtained by subtracting the background count from the uncorrected on peak count.

Due to the sample RW-1 is respectively uniform [3], compute an age for a few analytical spots, and after propagating uncertainties, accumulating enough points to obtain a meaningful age [1,5]. The dating results of total 10 analyses yield an average age of $904.9 \pm 4.0 \mathrm{Ma}$ (total points), $913.5 \pm 4.0 \mathrm{Ma}$ (removing positive outliers) and $889.1 \pm 4.0 \mathrm{Ma}$ (two-point). The age calculated by total points is consistent with the reference value. Therefore, the multipoint background analysis method is a reliable method for chemical dating of monazite. It can effectively solve the problems of non-linear background and serious background interference. However, care needs to be taken when removing outliers, as negative outliers may exist and the lowest is not equal to the best [7].

\section{References:}

[1] J M Montel et al, Chem. Geol. 484 (1996), p. 37.

[2] K Suzuki and M Adachi, Japan. J. Earth Sci. Nagoya Univ. 38 (1991), p. 11.

[3] X X Ling et al, Mineral. Petrol. 111 (2017), p. 1.

[4] J J Donovan, J W Singer and J T Armstrong, Am. Miner. 8 (2016), p. 1839.

[5] M J Jercinovic and M L Williams, Am. Miner. 90 (2005), p. 526.

[6] M J Jercinovic, M L Williams and E D Lane, Chem. Geol. 254 (2008), p. 197.

[7] The authors acknowledge funding from the National Key R\&D Plan of China (No.

2017YFC0601404) and the National Natural Science Foundation of China (No. 41773040).
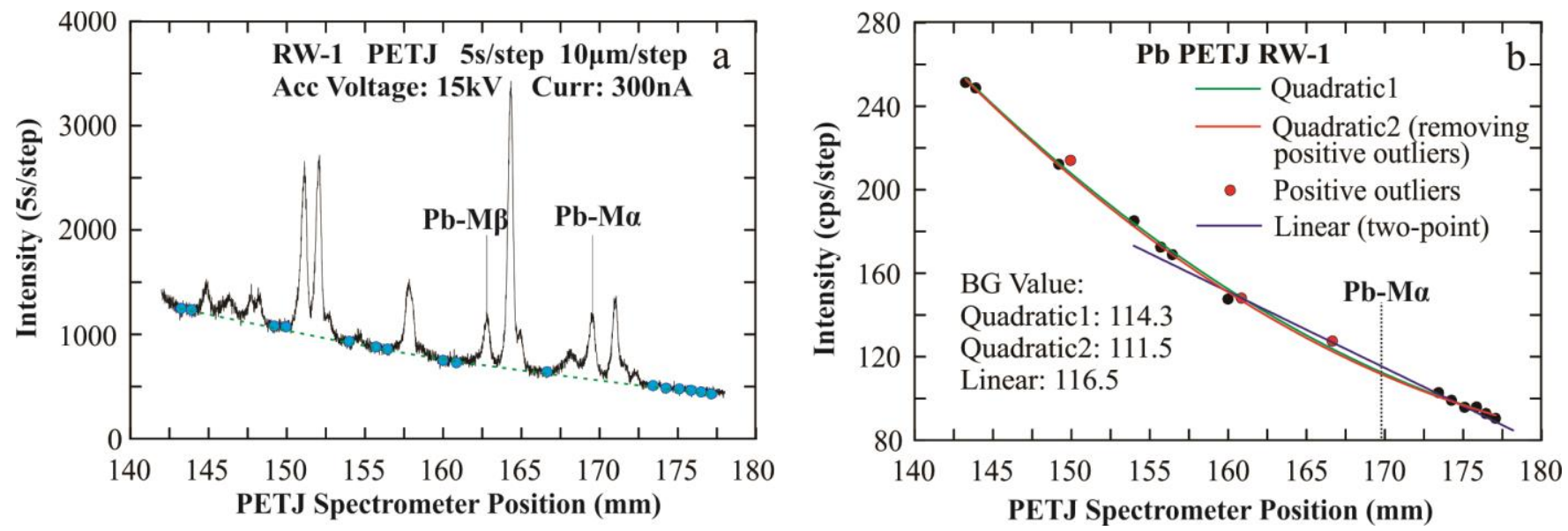

Figure 1. (a) Wavelength scanning of the $\mathrm{Pb}-\mathrm{M} \alpha$ and $\mathrm{Pb}-\mathrm{M} \beta$ region of PETJ, and (b) Fitting background curves of $\mathrm{Pb}$ using multipoint and two-point. 